\title{
Listeria monocytogenes and diet during pregnancy; balancing nutrient intake adequacy $v$. adverse pregnancy outcomes
}

\author{
Kristine B Pezdirc ${ }^{1}$, Alexis J Hure ${ }^{2}$, Michelle L Blumfield ${ }^{1,2}$ and Clare E Collins ${ }^{1, *}$ \\ ${ }^{1}$ School of Health Sciences, Faculty of Health, The University of Newcastle, HA12 Hunter Building, Callaghan, \\ NSW 2308, Australia: ${ }^{2}$ Mothers and Babies Research Centre, Hunter Medical Research Institute and University \\ of Newcastle, John Hunter Hospital, Callaghan, Australia
}

Submitted 19 June 2011: Final revision received 13 November 2011: Accepted 3 February 2012: First published online 8 March 2012

\begin{abstract}
Objective: To evaluate the impact of adherence to public health recommendations on Listeria monocytogenes food safety to limit exposure to potential food sources on micronutrient intakes of pregnant women and whether more frequent consumption of 'high-risk' foods increases risk for adverse pregnancy outcomes. Design: A cohort study in women assessing Listeria exposure from an FFQ based on consumption of potential Listeria-containing food sources, the Listeria Food Exposure Score (LFES). Pregnancy status was defined as pregnant, trying to conceive, had a baby within the previous 12 months, or other. Nutrient intakes were compared with Nutrient Reference Values and self-reported pregnancy outcome history three years later.

Setting: Australia.

Subjects: Women aged 25-30 years ( $n$ 7486) participating in the Australian Longitudinal Study on Women's Health.

Results: There were weak positive correlations $(r=0 \cdot 13-0 \cdot 37, \quad P<0 \cdot 001)$ between LFES and all nutrients, with fibre, folate, Fe and vitamin E intakes consistently below the Nutrient Reference Values in every quintile of LFES. Women in the highest quintile of LFES reported 19\% more miscarriages (rate ratio $=1 \cdot 19$; $95 \%$ CI $1 \cdot 02,1 \cdot 38$ ) than those in the lowest quintile, after adjusting for important confounding factors.

Conclusions: More frequent consumption of foods potentially containing L. monocytogenes is associated with higher nutrient intakes, but an increased risk of miscarriage. L. monocytogenes pregnancy recommendations require review and should include the list of 'risky' food items in addition to low-risk alternatives that would adequately replace nutrient intakes which may be reduced through avoidance strategies.
\end{abstract}

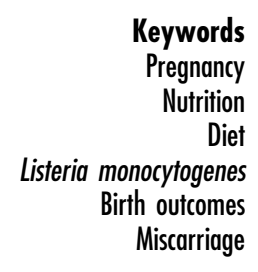

During pregnancy women are concerned about their diet and health ${ }^{(1)}$. Diet quality and maternal nutritional status have an important influence on health outcomes of both mother and infant ${ }^{(2,3)}$. Inadequate dietary intakes of folate, Fe, $\mathrm{Zn}$ and protein have been associated with neural tube and other birth defects ${ }^{(2,3)}$, fetal growth restriction $^{(2,3)}$ and increased risk of adverse long-term health outcomes for the offspring, such as $\mathrm{CVD}^{(2-5)}$ and type 2 diabetes ${ }^{(2-5)}$. Pregnant women require additional energy and specific nutrients including protein, folate, Fe, $\mathrm{Ca}, \mathrm{Zn}$ and other vitamins and minerals to ensure that their requirements and those of the developing fetus are $\mathrm{met}^{(5-7)}$. Simultaneously, they have an increased susceptibility to food-borne illness, particularly due to Listeria monocytogenes commonly found in ready-to-eat foods $^{(8)}$, secondary to hormonal changes that suppress the immune response and make them more vulnerable to infections ${ }^{(9)}$. Listeriosis is rare, with approximately sixtyfive cases reported in Australia during 2008; twelve (18\%) of which were in pregnancy ${ }^{(10)}$ and one was fatal ${ }^{(10)}$. Although the incidence in pregnancy is reportedly low, listeriosis is still considered an important public health issue due to the potentially serious impact on the fetus, including miscarriage, stillbirth, premature birth and/or neonatal infection ${ }^{(9,11,12)}$.

International nutrition and maternal health authorities have developed recommendations specifically to alert women to this issue in order to reduce risks during pregnancy $^{(8,13)}$. These guidelines recommend avoidance of specific 'high-risk' foods more likely to contain L. monocytogenes and following safe food handling, preparation and storage practices ${ }^{(8,13)}$. However many of the foods that women are advised to avoid, such as salads (fruit and lettuce), cold meats and soft cheeses, contain 
nutrients that pregnant women have a higher requirement for, such as Fe in meat and folate from vegetables and fruit $^{(14)}$. Consequently, having all pregnant women severely restrict all potential food sources of L. monocytogenes may have implications for diet quality and nutrient intakes, potentially increasing maternal and fetal risks secondary to suboptimal nutrient status. This presents a challenging issue for public health authorities and for pregnant women, as the risk of listeriosis $v$. inadequate nutrient intakes needs to weighed up ${ }^{(14)}$.

Some studies have examined the diet quality of pregnant women in relation to nutrient intakes ${ }^{(15-19)}$. Hure et al. found that women of childbearing age in Australia are not meeting key nutrient intakes and concluded that those who were trying to become pregnant or were pregnant did not appear to consume a variety of nutritious foods ${ }^{(15)}$. However, to the best of our knowledge, no study to date has examined the implications of adherence to L. monocytogenes recommendations on nutrient quality in pregnant women. The primary aim of the present study was therefore to establish whether the micronutrient intakes of pregnant women whose dietary intakes align with Listeria recommendations meet the pregnancy Nutrient Reference Values for Australia and New Zealand ${ }^{(20)}$ compared with those who consume 'high-risk' foods more frequently. The secondary aim was to determine whether more frequent consumption of potential L. monocytogenes food sources increases the risk of adverse birth outcomes, including premature birth, miscarriage and stillbirth.

\section{Experimental methods}

\section{Data collection}

The current study used self-reported data from participants in the young cohort of the Australian Longitudinal Study on Women's Health (ALSWH) which recruited 40000 women within three age cohorts: 'young', 'midaged' and 'older', in 1996. The study was approved by the Human Research Ethics Committees of the Universities of Newcastle and Queensland. Additional ALSWH details have been published elsewhere ${ }^{(21-23)}$. The current study focuses on women in the young cohort, who were 25-30 years of age at the time of completing an FFQ in Survey 3 (2003) and 28-33 years of age when reporting their birth outcomes in Survey 4 (2006).

ALSWH reports demographic details including sociodemographic characteristics, health behaviours and psychosocial measures. The Dietary Questionnaire for Epidemiological Studies (DQES) version 2, a seventyfour-item FFQ previously validated in young Australian women, was used to estimate usual dietary intake ${ }^{(24,25)}$. Participants were asked to report frequency of consumption of seventy-four food items over the previous 12 months using a 10-point frequency scale ranging from 'never' to 'three or more times per day ${ }^{, 24)}$. The DQES FFQ includes photographs of potato, vegetables, steak and casseroles to adjust for portion sizes. In addition, questions are asked on the usual daily servings of fruit, vegetables, dairy, bread, sugar, eggs and type of fat used ${ }^{(24)}$. NUTTAB 1995 , the most recent national government food composition database of Australian foods at that time, was used to compute nutrient intakes using software developed by the Cancer Council of Victoria ${ }^{(26)}$.

\section{Sample}

In 1996, a total of 14247 women aged 18-23 years participated in the baseline young cohort survey (Survey 1). Of these, 9076 completed Survey 3 in 2003. Based on the methodology of Hure et al. four groups were used to define pregnancy status: (i) pregnant ( $n$ 606); (ii) trying to conceive ( $n$ 454); (iii) had a baby in the last 12 months ( $n$ 829); and (iv) other $(n 5597)^{(15)}$. Women were excluded if: (i) their pregnancy status could not be determined from their survey response ( $n$ 111); (ii) they could be grouped into more than one pregnancy category ( $n$ 61); or (iii) their calculated energy intake was $<4.5 \mathrm{MJ} / \mathrm{d}$ ( $n$ 1398) or $>20 \cdot 0 \mathrm{MJ} / \mathrm{d}(n 20)^{(15)}$.

Following exclusion, data from a total of 7486 women were included in our analysis. The mean age for women participating in the young cohort in 2003 was $27 \cdot 6$ (SD 1.5) years. Demographic characteristics by pregnancy group have been described elsewhere ${ }^{(15)}$. Briefly, women who reported that they were currently pregnant, trying to conceive or had given birth in the last 12 months were more likely to be married or in a de facto relationship and to live in a rural area compared with women in the 'other' group. Women in the 'other' group were more likely to be born outside Australia, have post-school qualifications and be more physically active ${ }^{(15)}$.

\section{Listeria Food Exposure Score}

A Listeria Food Exposure Score (LFES) was developed based on alignment of foods listed in the DQES FFQ with the Australian Listeria recommendations ${ }^{(27)}$. Eleven potential food sources of Listeria were identified: (i) cheese, (ii) ice cream, (iii) chicken, (iv) bacon, (v) ham, (vi) luncheon meats or salami, (vii) lettuce, (viii) cabbage, (ix) cauliflower, (x) broccoli and (xi) bean sprouts or alfalfa sprouts ${ }^{(27)}$. The total LFES based on reported frequency of consumption was calculated, with food items that were never consumed scored as 0 , foods consumed less than once monthly scored as 1 , up to a maximum score of 9 for foods eaten three or more times daily. The maximum LFES possible, based on the most frequent consumption of all eleven food items, was 99.

\section{Nutrient Reference Values}

The Nutrient Reference Values for Australia and New Zealand, developed by the National Health and Medical Research Council of Australia, set target daily nutrient intake levels to maintain health or to prevent nutritional 
deficiency ${ }^{(20)}$. An Estimated Average Requirement (EAR) is a 'daily nutrient intake level needed to meet the requirements of half the healthy individuals in a particular life stage and gender group, ${ }^{, 20)}$. It is used to estimate the prevalence of inadequate intakes within a group. When there is no EAR available for a particular nutrient, Adequate Intake (AI) is used as an alternative. $\mathrm{AI}$ is the 'average daily nutrient intake level based on observed or experimentally determined approximations or estimates of nutrient intakes by a group (or groups) of apparently healthy people that are assumed to be adequate ${ }^{,(20)}$.

\section{Birtb outcomes}

In the follow-up Survey 4 (2006) women were asked to report how many times they had each of the following: 'live birth (>36 weeks)', 'live premature birth ( $\leq 36$ weeks)', 'stillbirth' and 'miscarriage', using frequency response category from 'none' up to 'five or more'. A total of 6931 women completed both the DQES FFQ in Survey 3 and reported their birth outcomes in Survey 4.

\section{Statistical analysis}

Descriptive statistics were used to calculate the mean score and standard deviation for each of the Listeria food item sub-scales and the total LFES by pregnancy status. Comparisons between the mean LFES and pregnancy groups were conducted by using two-sample $t$ tests. The differences between the pregnancy groups and Listeria food items were calculated by using one-way ANOVA and post hoc Tukey Honestly Significant Difference analyses. LFES were divided into quintiles and the differences between the quintiles for macro- and micronutrients were observed using ANOVA. Pearson's correlation was used to test for associations between quintiles and nutrients.

Stepwise multiple regression (Poisson) with backward selection $(P<0 \cdot 2)$ was used to model the incidence rate ratios of the birth outcomes, i.e. preterm birth (live, $\leq 36$ weeks' gestation), stillbirth and miscarriage, reported at Survey 4. LFES quintile (from Survey 3) was used as the main predictor of birth outcome, with and without adjustment for the potential confounding factors identified by Morrison et al:: smoking, maternal age, parity, alcohol and $\mathrm{BMI}^{(28)}$.

All $P<0.05$ were considered statistically significant. Regression analyses were performed using the Intercooled Stata statistical software package version 11 (StataCorp LP, College Station, TX, USA). All other data analyses were performed using the JMP statistical software package for Windows, version 8 (SAS Institute Inc., Cary, NC, USA).

\section{Results}

Table 1 reports mean LFES by pregnancy status. The highest LFES was 63, and the lowest was 0 . Women who were trying to conceive or had given birth in the last
Table 1 Mean LFES, with their standard deviations, for the young cohort of women in the Australian Longitudinal Study on Women's Health, by pregnancy status

\begin{tabular}{lrrlll}
\hline Pregnancy status & $n$ & $\%$ & Mean & SD & $P$ value* \\
\hline Pregnant & 606 & $8 \cdot 1$ & $29 \cdot 9$ & $7 \cdot 5$ & 0.201 \\
Trying to conceive & 454 & $6 \cdot 1$ & $30 \cdot 8+$ & 8.0 & 0.001 \\
Birth <12 months ago & 829 & $11 \cdot 1$ & $31 \cdot 7 \dagger$ & $7 \cdot 8$ & 0.001 \\
Other & 5597 & $74 \cdot 8$ & $29 \cdot 5$ & $7 \cdot 8$ & \\
\hline
\end{tabular}

LFES, Listeria Food Exposure Score (maximum = 99).

${ }^{\star} P$ values calculated using two-sample $t$ tests.

tMean value was significantly different compared with the 'other' group $(P<0 \cdot 05)$.

12 months had significantly higher LFES than women in the 'other' group $(P=0 \cdot 001)$, with no significant difference between the pregnant and 'other' groups $(P=0 \cdot 201)$.

Table 2 reports mean scores for individual food items making up the total LFES, by pregnancy status. Overall, cheese had the highest consumption frequency of items in the LFES among all pregnancy groups, while bean sprouts or alfalfa sprouts had the lowest. Pregnant women consumed cheese and ice cream significantly more frequently than women in the 'other' group. However, they consumed lettuce, endive or other salad greens less frequently $(P<0.001)$ than those in the 'other' group. Women who had given birth $<12$ months ago had significantly higher consumption frequencies for cheese, bacon, ham, cauliflower and broccoli compared with the 'other' group $(P<0 \cdot 001)$. There were no differences in the consumption frequency of chicken and cabbage across groups. Where there were statistically significant differences among pregnancy groups, the differences were less than or equal to 1 point.

Table 3 reports the mean and standard deviation of macro- and micronutrient intakes by quintile of LFES. Across all nutrients and quintiles, there were weak positive correlations between macro- and micronutrient intakes, that increased as LFES quintile increased $(r=0 \cdot 13-0 \cdot 37$, $P<0 \cdot 001$ ). On the contrary, as the LFES increased, the percentage of energy from carbohydrate decreased and the percentage of energy from total and saturated fat increased. The mean intakes for protein, retinol equivalents, niacin, riboflavin, thiamin, vitamin $\mathrm{C}, \mathrm{Na}$ and $\mathrm{Zn}$ were above the EAR or AI in all LFES quintiles. Fibre, folate, Fe and vitamin $\mathrm{E}$ were consistently below the EAR or AI. K was below the EAR in quintile 1 to quintile 3 . Ca was below the EAR in quintile 1.

Table 4 reports the rate ratios (RR) of birth outcomes reported at Survey 4 by quintile of the LFES. In the unadjusted models, women in LFES quintile 5 (highest) reported significantly $(P<0 \cdot 05)$ more premature deliveries $(\mathrm{RR}=1 \cdot 44 ; 95 \% \mathrm{CI} 1 \cdot 15,1 \cdot 80)$, stillbirths $(\mathrm{RR}=1 \cdot 94$; $95 \%$ CI $1 \cdot 22,3 \cdot 08)$ and miscarriages $(\mathrm{RR}=1 \cdot 34 ; 95 \% \mathrm{CI}$ $1 \cdot 16,1 \cdot 55)$ compared with the women in the lowest LFES (quintile 1). Following adjustment for smoking, maternal age, parity, BMI and alcohol intake, women in LFES quintile 5 reported $19 \%$ more miscarriages $(\mathrm{RR}=1 \cdot 19$; $95 \%$ CI $1.02,1.38 ; P<0 \cdot 05)$ than the women in the 
Table 2 Mean Listeria food group sub-scale scores and total LFES, with their standard deviations, for the young cohort of women in the Australian Longitudinal Study on Women's Health, by pregnancy status

\begin{tabular}{|c|c|c|c|c|c|c|c|c|c|}
\hline \multirow[b]{2}{*}{ Food item (maximum score) } & \multicolumn{2}{|c|}{$\begin{array}{c}\text { Pregnant } \\
(n 606,8 \cdot 1 \%)\end{array}$} & \multicolumn{2}{|c|}{$\begin{array}{l}\text { Trying to conceive } \\
\quad(n 454,6 \cdot 1 \%)\end{array}$} & \multicolumn{2}{|c|}{$\begin{array}{c}\text { Birth }<12 \text { months } \\
\text { ago } \\
(n 829,11 \cdot 1 \%)\end{array}$} & \multicolumn{2}{|c|}{$\begin{array}{c}\text { Other } \\
\text { ( } n 5597,74 \cdot 8 \%)\end{array}$} & \multirow[b]{2}{*}{$P$ value ${ }^{\star}$} \\
\hline & Mean & SD & Mean & SD & Mean & SD & Mean & SD & \\
\hline Cheese (9) & $5 \cdot 0+$ & $1 \cdot 7$ & $4 \cdot 8$ & $1 \cdot 8$ & $5 \cdot 2+$ & $1 \cdot 8$ & $4 \cdot 7$ & $1 \cdot 9$ & $<0.001$ \\
\hline Ice cream (9) & $2 \cdot 7 \dagger$ & $1 \cdot 6$ & $2 \cdot 5+$ & 1.5 & $2 \cdot 7 \dagger$ & $1 \cdot 7$ & $2 \cdot 2$ & $1 \cdot 5$ & $<0.001$ \\
\hline Chicken (9) & $3 \cdot 8$ & $1 \cdot 2$ & $4 \cdot 0$ & $1 \cdot 2$ & $4 \cdot 0$ & $1 \cdot 2$ & $3 . \overline{9}$ & 1.5 & 0.016 \\
\hline Bacon (9) & $1 \cdot 8$ & $1 \cdot 1$ & 1.9 & $1 \cdot 2$ & $2 \cdot 0 t$ & $1 \cdot 2$ & $1 \cdot 8$ & $1 \cdot 3$ & $<0.001$ \\
\hline Ham (9) & $2 \cdot 5$ & $1 \cdot 7$ & $2 \cdot 7 \dagger$ & $1 \cdot \overline{8}$ & $3 \cdot 0 t$ & $1 \cdot \overline{8}$ & $2 \cdot 5$ & $1 \cdot 7$ & $<0.001$ \\
\hline Corned beef, luncheon meats or salami (9) & $1 \cdot 7$ & $1 \cdot 6$ & $1 \cdot 8$ & $1 \cdot 6$ & $1.9+$ & $1 \cdot 6$ & $1 \cdot 7$ & $1 \cdot 6$ & 0.0004 \\
\hline Lettuce, endive or other salad greens (9) & $3 \cdot 7+$ & $1 \cdot 6$ & $4 \cdot 0$ & $1 \cdot 7$ & $3 \cdot 9$ & $1 \cdot 7$ & $4 \cdot 0$ & $1 \cdot 7$ & 0.002 \\
\hline Cabbage (9) & $1 \cdot 6$ & $1 \cdot 7$ & $1 \cdot 6$ & $1 \cdot 7$ & $1 \cdot 6$ & $1 \cdot 7$ & $1 \cdot 7$ & $1 \cdot 6$ & 0.690 \\
\hline Cauliflower (9) & $2 \cdot 5$ & $1 \cdot 8$ & $2 \cdot 6$ & $1 \cdot 9$ & $2 \cdot 7 \dagger$ & $1 \cdot 9$ & $2 \cdot 4$ & $1 \cdot 8$ & $<0.001$ \\
\hline Broccoli (9) & $3 \cdot 5$ & $1 \cdot 8$ & $3 \cdot 6$ & $1 \cdot 9$ & $3 \cdot 7 t$ & $1 \cdot 9$ & $3 \cdot 4$ & $1 \cdot 8$ & $<0.001$ \\
\hline Bean sprouts or alfalfa sprouts (9) & $1 \cdot 0 t$ & $1 \cdot 2$ & $1 \cdot 1$ & $1 \cdot 4$ & $1 \cdot 0 t$ & $1 \cdot 3$ & $1 \cdot 3$ & 1.5 & $<0.001$ \\
\hline LFES (99) & $29 \cdot 9$ & $7 \cdot 5$ & $30 \cdot 8+$ & $8 \cdot 0$ & $31 \cdot 7 \dagger$ & $7 \cdot 8$ & $29 \cdot 5$ & $7 \cdot 9$ & $<0.001$ \\
\hline
\end{tabular}

LFES, Listeria Food Exposure Score.

${ }^{*} P$ values from one-way ANOVA.

tMean value was significantly different from that of the 'other' group using Tukey post hoc analysis $(P<0.001)$.

lowest LFES quintile. LFES was not a significant predictor of live term births after adjustment for confounding factors.

\section{Discussion}

The current study indicates that women of childbearing age who frequently consumed foods that potentially contain L. monocytogenes experienced significantly more miscarriages. However, moderate consumption of these foods was not associated with an increased risk of adverse birth outcomes. This has important implications for public health nutrition because more frequent consumption of foods that potentially contain Listeria has simultaneously been associated with higher intakes of nutrients important during pregnancy. The present study is the first that has examined the nutrient intakes of pregnant women who adhere to Listeria recommendations.

We did not find that those who were currently pregnant had lower LFES, while the mean LFES among those trying to conceive or who had given birth in the previous 12 months was slightly higher compared with the 'other' group. Although there were significant differences between pregnancy groups in the consumption of several food items, the differences were small (all less than 1 point). This shows that no single food contributed to the observed differences between pregnancy groups in the total LFES.

Levels of all of the selected macro- and micronutrients increased with increasing quintile of LFES, with the lowest quintile consistently having a more adverse nutrient profile than the highest quintile. Those in the lowest LFES quintile had consumption frequencies for the majority (73\%) of potential Listeria food sources ranging from once monthly up to one to three times weekly, and this was associated with the lowest intakes of total energy, fibre, folate, $\mathrm{Fe}$, vitamin $\mathrm{E}$ and $\mathrm{Ca}$, with all lower than the
EAR or AI. This is a major concern, as suboptimal intakes of these nutrients can also adversely impact on the health outcomes of both the mother and infant ${ }^{(2-5)}$. This indicates that pregnant women who comply with the Listeria recommendations and consciously limit their consumption of potential Listeria-containing foods are likely to have suboptimal nutrient intake from foods.

It was found that the highest LFES quintile was associated with the highest nutrient intakes. However, even these women were still unable to achieve the recommended EAR or AI of the selected micronutrients folate, $\mathrm{Fe}$, fibre and vitamin $\mathrm{E}$. These findings highlight that more frequent consumption of potential Listeria-containing foods does increase nutrient intakes, especially of fibre, folate and Fe, but that even in this highest LFES quintile intakes of these nutrients remain marginal. Interestingly, it was observed that as the LFES increased the percentage of energy from fat and saturated fat increased and that from carbohydrate decreased. The increase in frequency of consumption of cheese, ice cream and meat would have contributed to this pattern as these foods have a higher energy density and contain more saturated fat, contributing to an increase in total energy.

The current study has found that eating patterns in women that include frequent consumption of foods potentially contaminated with Listeria are associated with higher rates of miscarriage compared with infrequent consumption. Moderate intake, as indicated by LFES quintile 3, had no increased association with adverse birth outcomes compared with a low consumption. Therefore it appears reasonable to suggest that to balance the opposing risks, pregnant women should aim for moderate consumption of potential Listeria-containing foods as opposed to a low consumption or total exclusion, which comes at the expense of important nutrients for pregnancy. To achieve a moderate consumption, pregnant 
Table 3 Macro- and micronutrient intakes by LFES quintile for the young cohort of women in the Australian Longitudinal Study on Women's Health who completed an FFQ ( $n$ 7486)

\begin{tabular}{|c|c|c|c|c|c|c|c|c|c|c|c|c|}
\hline \multirow[b]{2}{*}{ Nutrient } & \multirow[b]{2}{*}{ NRV } & \multicolumn{2}{|c|}{$\begin{array}{c}\text { Quintile 1 } \\
\text { (n 1564, 20.9\%) }\end{array}$} & \multicolumn{2}{|c|}{$\begin{array}{c}\text { Quintile 2 } \\
\text { (n 1736, 23.2\%) }\end{array}$} & \multicolumn{2}{|c|}{$\begin{array}{c}\text { Quintile 3 } \\
\text { (n 1512, 20.2\%) }\end{array}$} & \multicolumn{2}{|c|}{$\begin{array}{c}\text { Quintile } 4 \\
\text { (n 1267, 16.9\%) }\end{array}$} & \multicolumn{2}{|c|}{$\begin{array}{c}\text { Quintile 5 } \\
\text { (n 1407, 18.8\%) }\end{array}$} & \multirow[b]{2}{*}{ Correlation $(r)$} \\
\hline & & Mean & SD & Mean & SD & Mean & SD & Mean & SD & Mean & SD & \\
\hline Total energy (kJ) & $n / a$ & $6811 \cdot 6$ & $2052 \cdot 9$ & $7068 \cdot 2$ & $2038 \cdot 6$ & $7430 \cdot 9$ & $2174 \cdot 1$ & $7696 \cdot 8$ & $2188 \cdot 8$ & $8805 \cdot 5$ & $2912 \cdot 9$ & $0 \cdot 28$ \\
\hline Carbohydrate $(\mathrm{g})$ & $\mathrm{n} / \mathrm{a}$ & $189 \cdot 1$ & 62.5 & 189.9 & $58 \cdot 8$ & 193.9 & 59.9 & $196 \cdot 7$ & $59 \cdot 1$ & $216 \cdot 5$ & $75 \cdot 1$ & 0.13 \\
\hline Carbohydrate (\%E) & $45-65$ & $46 \cdot 4$ & $6 \cdot 3$ & $45 \cdot 0$ & $6 \cdot 0$ & $43 \cdot 7$ & $5 \cdot 5$ & $42 \cdot 8$ & $5 \cdot 5$ & $41 \cdot 3$ & $6 \cdot 0$ & -0.29 \\
\hline Fibre $(\mathrm{g})$ & Al 28 & $18 \cdot 8$ & $7 \cdot 4$ & $19 \cdot 2$ & $7 \cdot 2$ & $19 \cdot 7$ & $6 \cdot 8$ & $20 \cdot 1$ & $6 \cdot 4$ & $22 \cdot 6$ & $7 \cdot 7$ & $0 \cdot 17$ \\
\hline Sugars (g) & $\mathrm{n} / \mathrm{a}$ & $81 \cdot 2$ & $32 \cdot 6$ & $83 \cdot \overline{5}$ & $30 \cdot 4$ & $85 \cdot 4$ & $29 \cdot 4$ & $87 \cdot 4$ & $31 \cdot 2$ & $97 \cdot 3$ & $36 \cdot 2$ & $0 \cdot 16$ \\
\hline Protein $(\mathrm{g})$ & EAR $49^{*}$ & 73.9 & 23.9 & $81 \cdot 6$ & $25 \cdot 8$ & $87 \cdot 7$ & $26 \cdot 4$ & $92 \cdot 5$ & $26 \cdot 7$ & $110 \cdot 2$ & $38 \cdot 6$ & 0.38 \\
\hline Protein (\%E) & $15-25$ & $18 \cdot 3$ & $3 \cdot 2$ & $19 \cdot 4$ & 3.0 & $19 \cdot 9$ & $2 \cdot 8$ & $20 \cdot 2$ & 3.0 & $21 \cdot 1$ & $3 \cdot 3$ & $0 \cdot 29$ \\
\hline Total fat $(\mathrm{g})$ & $\mathrm{n} / \mathrm{a}$ & $64 \cdot 7$ & $23 \cdot \overline{8}$ & $67 \cdot 8$ & $23 \cdot 8$ & $72 \cdot 9$ & $25 \cdot 8$ & $76 \cdot \overline{6}$ & $26 \cdot 3$ & $89 \cdot 5$ & 34.9 & 0.29 \\
\hline Total fat (\%E) & $20-35$ & 34.9 & $6 \cdot 0$ & $35 \cdot 2$ & 5.5 & $36 \cdot 0$ & $5 \cdot 3$ & $36 \cdot 5$ & $5 \cdot 0$ & $37 \cdot 2$ & $5 \cdot 3$ & $0 \cdot 15$ \\
\hline SFA (g) & $\mathrm{n} / \mathrm{a}$ & $26 \cdot 7$ & $11 \cdot 2$ & $28 \cdot 3$ & $11 \cdot 2$ & 30.5 & $12 \cdot 0$ & $32 \cdot 0$ & $12 \cdot 3$ & 37.9 & $16 \cdot 2$ & 0.28 \\
\hline SFA (\%E) & $8-10$ & $14 \cdot 4$ & $3 \cdot \overline{6}$ & $14 \cdot 7$ & $3 \cdot 3$ & $15 \cdot 0$ & $3 \cdot 2$ & $15 \cdot 2$ & 3.0 & $15 \cdot 7$ & 3.0 & 0.13 \\
\hline PUFA (g) & $\mathrm{n} / \mathrm{a}$ & $9 \cdot 7$ & $4 \cdot 8$ & $9 \cdot 7$ & $4 \cdot 3$ & $10 \cdot 3$ & $4 \cdot 6$ & $10 \cdot 7$ & $4 \cdot 7$ & $11 \cdot 7$ & $5 \cdot 0$ & $0 \cdot 15$ \\
\hline MUFA (g) & $\mathrm{n} / \mathrm{a}$ & $22 \cdot 4$ & $8 \cdot 8$ & $23 \cdot 7$ & 8.6 & $25 \cdot 7$ & $9 \cdot 4$ & $27 \cdot 1$ & 9.5 & $32 \cdot 0$ & $12 \cdot 9$ & $0 \cdot 30$ \\
\hline$R E(\mu \mathrm{g})$ & EAR 550 & $704 \cdot 8$ & $299 \cdot 0$ & $729 \cdot 4$ & $273 \cdot 7$ & $775 \cdot 7$ & $283 \cdot 2$ & $809 \cdot 2$ & $281 \cdot 5$ & $890 \cdot 8$ & $306 \cdot 0$ & $0 \cdot 22$ \\
\hline Folate $(\mu \mathrm{g})$ & EAR $520+$ & $239 \cdot 1$ & $94 \cdot 3$ & $252 \cdot 4$ & 92.5 & $264 \cdot 1$ & 87.5 & 273.5 & $87 \cdot 8$ & 312.5 & $106 \cdot 3$ & 0.24 \\
\hline Niacin (mg) & EAR 14 & $18 \cdot 4$ & $7 \cdot 6$ & 20 & $7 \cdot 5$ & $21 \cdot 2$ & $7 \cdot 7$ & $22 \cdot 2$ & $7 \cdot 7$ & $26 \cdot 3$ & $10 \cdot 2$ & 0.29 \\
\hline Riboflavin (mg) & EAR 1.2 & $2 \cdot 1$ & 0.9 & $2 \cdot 3$ & 0.8 & $2 \cdot 4$ & 0.8 & $2 \cdot \overline{5}$ & 0.9 & $2 \cdot 8$ & $1 \cdot 1$ & 0.24 \\
\hline Thiamin (mg) & EAR 1.2 & $1 \cdot 4$ & 0.6 & 1.5 & 0.6 & 1.5 & 0.6 & 1.6 & 0.6 & $1 \cdot 8$ & 0.7 & 0.22 \\
\hline Vitamin C (mg) & EAR 40 & $119 \cdot 3$ & $79 \cdot 1$ & $125 \cdot 6$ & $76 \cdot 6$ & $130 \cdot 4$ & $68 \cdot 3$ & $136 \cdot 7$ & 73.9 & 155.9 & $80 \cdot 5$ & $0 \cdot 15$ \\
\hline Vitamin E (mg) & EAR 7 & $5 \cdot 7$ & $2 \cdot 3$ & $5 \cdot 6$ & $2 \cdot 1$ & $5 \cdot 8$ & $2 \cdot 0$ & $6 \cdot 0$ & $2 \cdot 1$ & $6 \cdot 6$ & $2 \cdot 4$ & $0 \cdot 15$ \\
\hline $\mathrm{Ca}(\mathrm{mg})$ & EAR 840 & $797 \cdot 7$ & $286 \cdot 1$ & $855 \cdot 5$ & $270 \cdot 8$ & 905.9 & $269 \cdot 6$ & $934 \cdot 1$ & $281 \cdot 3$ & $1035 \cdot 1$ & 319.5 & 0.26 \\
\hline $\mathrm{Fe}(\mathrm{mg})$ & EAR 22 & 10.9 & $4 \cdot 3$ & $11 \cdot 7$ & $4 \cdot 3$ & $12 \cdot 2$ & $4 \cdot 4$ & $12 \cdot 6$ & $4 \cdot 2$ & $14 \cdot 8$ & $5 \cdot 6$ & 0.26 \\
\hline $\mathrm{Na}(\mathrm{mg})$ & $\begin{array}{l}\text { Al } 460-920 \\
\text { UL } 2300\end{array}$ & $2121 \cdot 8$ & $696 \cdot 9$ & $2299 \cdot 9$ & $703 \cdot 8$ & $2475 \cdot 5$ & $767 \cdot 8$ & $2613 \cdot 7$ & $795 \cdot 7$ & $3087 \cdot 6$ & $1056 \cdot 4$ & 0.36 \\
\hline $\mathrm{K}(\mathrm{mg})$ & Al 2800 & $2498 \cdot 8$ & $775 \cdot 6$ & $2609 \cdot 3$ & $764 \cdot 6$ & $2733 \cdot 2$ & 754 & $2809 \cdot 2$ & $761 \cdot 4$ & $3185 \cdot 8$ & 935 & 0.27 \\
\hline $\mathrm{Zn}(\mathrm{mg})$ & EAR 9.0 & 9.5 & $3 \cdot 4$ & $10 \cdot 5$ & $3 \cdot 6$ & $11 \cdot 3$ & $3 \cdot 7$ & $12 \cdot 0$ & $3 \cdot 7$ & $14 \cdot 3$ & $5 \cdot 3$ & 0.37 \\
\hline LFES & & $19 \cdot 3$ & $3 \cdot 6$ & $26 \cdot 2$ & $1 \cdot 4$ & $30 \cdot 4$ & $1 \cdot 1$ & $34 \cdot 4$ & $1 \cdot 1$ & $41 \cdot 4$ & $4 \cdot 3$ & \\
\hline
\end{tabular}

LFES, Listeria Food Exposure Score; NRV, Nutrient Reference Value (applicable to pregnant women aged 19-30 years ${ }^{(20)}$ ); \%E, percentage of energy; RE, retinol equivalents; $\mathrm{n} / \mathrm{a}$, not applicable; Al, Adequate Intake; EAR, Estimated Average Requirement; UL, Upper Limit.

Quintile 1 = lowest quintile of LFES; quintile $5=$ highest.

Quintile $1=$ correlations between nutrients and LFES quintiles were statistically significant at $P<0.001$.

Energy conversion factors for carbohydrates, protein and fat were $16.7 \mathrm{~kJ} / \mathrm{g}, 16 \cdot 7 \mathrm{~kJ} / \mathrm{g}$ and $37 \mathrm{~kJ} / \mathrm{g}$, respectively.

*Based on second and third trimesters.

tDietary intake only, does not include supplements. 
Table 4 Rate ratios of birth outcomes (reported at Survey 4) by LFES quintile (at Survey 3) for the young cohort of women in the Australian Longitudinal Study on Women's Health ( $n$ 6391)

\begin{tabular}{|c|c|c|c|c|c|c|c|c|c|}
\hline \multirow[b]{2}{*}{ Pregnancy outcome } & \multirow{2}{*}{$\begin{array}{c}\text { Predictor: } \\
\text { LFES quintile* }\end{array}$} & \multicolumn{3}{|c|}{$n$} & \multicolumn{2}{|c|}{ Unadjusted } & \multirow{2}{*}{$\begin{array}{l}\text { Confounderst } \\
\text { remaining in model }\end{array}$} & \multicolumn{2}{|c|}{ Adjusted } \\
\hline & & 0 & 1 & $>1$ & Rate ratio & $95 \% \mathrm{Cl}$ & & Rate ratio & $95 \% \mathrm{Cl}$ \\
\hline Live term birth & $\begin{array}{l}1 \\
2 \\
3 \\
4 \\
5\end{array}$ & $\begin{array}{l}719 \\
803 \\
628 \\
524 \\
517\end{array}$ & $\begin{array}{l}295 \\
349 \\
329 \\
288 \\
262\end{array}$ & $\begin{array}{r}882 \\
910 \\
903 \\
783 \\
1054\end{array}$ & $\begin{array}{l}1 \cdot 00 \\
0 \cdot 98 \\
1 \cdot 05 \\
1 \cdot 08 \\
1 \cdot 26\end{array}$ & \begin{tabular}{c}
\multicolumn{1}{c}{ Ref. } \\
$0 \cdot 92,1 \cdot 04$ \\
$0 \cdot 99,1 \cdot 12$ \\
$1 \cdot 02,1 \cdot 15 \ddagger$ \\
$1 \cdot 19,1 \cdot 33 \ddagger$
\end{tabular} & $\begin{array}{c}\text { Smoking } \\
\text { Maternal age } \\
\text { Parity }\end{array}$ & $\begin{array}{c}- \\
- \\
- \\
- \\
- \\
1.44 \\
1.02 \\
0.93\end{array}$ & $\begin{array}{c}- \\
- \\
- \\
- \\
- \\
1 \cdot 41,1 \cdot 48 \ddagger \\
1.01,1 \cdot 04 \ddagger \\
0.93,0.94 \ddagger\end{array}$ \\
\hline Preterm birth (live, $\leq 36$ weeks) & $\begin{array}{l}1 \\
2 \\
3 \\
4 \\
5\end{array}$ & $\begin{array}{l}1258 \\
1414 \\
1244 \\
1041 \\
1093\end{array}$ & $\begin{array}{l}57 \\
67 \\
53 \\
46 \\
66\end{array}$ & $\begin{array}{r}7 \\
6 \\
11 \\
14 \\
14\end{array}$ & $\begin{array}{l}1 \cdot 00 \\
0 \cdot 91 \\
1 \cdot 23 \\
1 \cdot 26 \\
1 \cdot 44\end{array}$ & \begin{tabular}{l}
\multicolumn{1}{c}{ Ref. } \\
$0 \cdot 72,1 \cdot 16$ \\
$0 \cdot 96,1 \cdot 57$ \\
$0 \cdot 99,1 \cdot 62$ \\
$1 \cdot 15,1 \cdot 80 \ddagger$
\end{tabular} & $\begin{array}{c}\text { Smoking } \\
\text { Maternal age } \\
\text { Parity } \\
\text { Alcohol }\end{array}$ & $\begin{array}{c}- \\
- \\
- \\
- \\
- \\
1 \cdot 06 \\
1.02 \\
1 \cdot 81 \\
1.07\end{array}$ & $\begin{array}{c}- \\
- \\
- \\
- \\
- \\
1 \cdot 01,1 \cdot 11 \ddagger \\
0 \cdot 99,1 \cdot 04 \\
1 \cdot 74,1 \cdot 88 \ddagger \\
0.99,1 \cdot 15\end{array}$ \\
\hline Stillbirth & $\begin{array}{l}1 \\
2 \\
3 \\
4 \\
5\end{array}$ & $\begin{array}{l}1313 \\
1477 \\
1293 \\
1095 \\
1153\end{array}$ & $\begin{array}{r}8 \\
10 \\
12 \\
5 \\
17\end{array}$ & $\begin{array}{l}1 \\
0 \\
1 \\
0 \\
1\end{array}$ & $\begin{array}{l}1 \cdot 00 \\
0 \cdot 60 \\
1 \cdot 09 \\
0.54 \\
1.94\end{array}$ & \begin{tabular}{l}
\multicolumn{1}{c}{ Ref. } \\
$0 \cdot 33,1 \cdot 06$ \\
$0 \cdot 65,1 \cdot 82$ \\
$0 \cdot 28,1 \cdot 03$ \\
$1 \cdot 22,3 \cdot 08 \ddagger$
\end{tabular} & $\begin{array}{l}\text { Smoking } \\
\text { Parity }\end{array}$ & $\begin{array}{c}- \\
- \\
- \\
- \\
- \\
0.90 \\
2 \cdot 17\end{array}$ & $\begin{array}{c}- \\
- \\
- \\
- \\
- \\
0 \cdot 79,1 \cdot 03 \\
1 \cdot 99,2 \cdot 37 \ddagger\end{array}$ \\
\hline Miscarriage & $\begin{array}{l}1 \\
2 \\
3 \\
4 \\
5\end{array}$ & $\begin{array}{r}1125 \\
1280 \\
1102 \\
898 \\
941\end{array}$ & $\begin{array}{l}145 \\
148 \\
157 \\
151 \\
170\end{array}$ & $\begin{array}{l}51 \\
58 \\
46 \\
48 \\
61\end{array}$ & $\begin{array}{l}1.00 \\
0.87 \\
0.98 \\
1.06 \\
1.34\end{array}$ & \begin{tabular}{l}
\multicolumn{1}{c}{ Ref. } \\
$0 \cdot 75,1 \cdot 02$ \\
$0 \cdot 84,1 \cdot 15$ \\
$0 \cdot 90,1 \cdot 24$ \\
$1 \cdot 16,1 \cdot 55 \ddagger$
\end{tabular} & $\begin{array}{l}\text { Smoking } \\
\text { Maternal age } \\
\text { Parity } \\
\text { BMI }\end{array}$ & $\begin{array}{l}1.00 \\
0.94 \\
0.99 \\
1.06 \\
1.19 \\
1.06 \\
0.99 \\
1.33 \\
1.01\end{array}$ & $\begin{array}{c}\text { Ref. } \\
0 \cdot 80,1 \cdot 11 \\
0 \cdot 84,1 \cdot 16 \\
0 \cdot 89,1 \cdot 26 \\
1 \cdot 02,1 \cdot 38 \ddagger \\
1 \cdot 03,1 \cdot 10 \ddagger \\
0 \cdot 97,1 \cdot 00 \\
1 \cdot 27,1 \cdot 39 \ddagger \\
1 \cdot 00,1 \cdot 02 \ddagger\end{array}$ \\
\hline
\end{tabular}

LFES, Listeria Food Exposure Score; Ref., referent category.

*LFES quintile $1=$ lowest; quintile $5=$ highest.

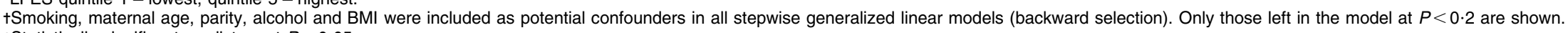

Statistically significant predictors at $P<0.05$. 
women could increase their intake of vegetables such as lettuce, cabbage and broccoli, which were observed to be consumed less frequently among this group, and this would increase their folate intakes. In addition it is recommended that a greater emphasis be placed on safe food handling, preparation and storage procedures for foods that may contain Listeria, as a key strategy to reducing risk.

A strength of the current study is the large sample size that was representative of the broad Australian population of women of childbearing age. However, the limitations need to be acknowledged. All potential risky foods were not included in the FFQ such as pâté, raw or uncooked seafood, pre-packaged food and fruit salad, and for some questions food items were grouped. For example, cheese includes all types, whereas only soft cheeses are considered a potential Listeria risk. The LFES was based on the frequency of consumption of food items. The study did not take into consideration the potential degree of contamination within each food or the likely prevalence of $L$. monocytogenes among the different pregnancy groups. Therefore risk is not likely to be homogeneous. Future studies that weight the LFES using biological data from food surveys are warranted. An important component of the public health recommendations focuses on safe food handling practices and this was not evaluated in ALSHW. Further, FFQ are subject to both recall and response bias and measurement error, with foods consumed closer to the time of completion more likely to be reported frequently. ALSWH did not measure vitamin or mineral supplementation which could increase nutrient intakes across all pregnancy groups, and meta-analysed randomized controlled trial data show that micronutrient supplementation can affect birth outcomes, including both increasing ${ }^{(29)}$ and decreasing ${ }^{(30)}$ the relative risk of preterm birth depending on the types of supplements that are used. Survey 4 asked women to report how many times they ever had each of the birth outcomes listed; therefore we cannot establish the time period in which these women experienced a miscarriage, stillbirth or premature birth. Under-reporting of pregnancy outcomes such as miscarriages may have occurred as women may choose not to reveal this information, especially if they have had several miscarriages ${ }^{(31)}$. Although the study was able to adjust for some potential confounding factors, other known causes of adverse pregnancy outcomes including aneuploidies, pre-eclampsia, fetal growth restriction and antepartum haemorrhage were not considered or adjusted for. The link between the LFES and rate of miscarriage would be greatly strengthened by prospective data that include laboratory testing for L. monocytogenes infection.

Adequate nutrition during pregnancy and listerosis prevention are important public health issues. An initiative to promote consumption of healthy and nutritious foods to those pregnant or considering a pregnancy is warranted. Rather than concentrating on what foods women should avoid, the focus needs to be on what they can safely consume and how to achieve this. Current recommendations directed at pregnant women to reduce L. monocytogenes food poisoning require review. The recommendations should include the list of 'risky' food items and should present low-risk alternatives that would help women to meet their optimal nutrient targets. For example, rather than a focus on exclusion of $\mathrm{X}$, an important source of $\mathrm{Y}$, women could be advised to consume A or B as lower-risk nutrient sources. In addition, the recommendations should emphasize the importance of safe food handling procedures. This will help to achieve a balance between potential benefit and harm associated with restricting specific foods and will help to build the evidence base in relation to prevention of listeriosis during pregnancy.

\section{Conclusions}

The current study is the first that has examined the nutrient intake profiles of pregnant women in relation to adherence to recommendations for avoiding Listeria poisoning and risk of adverse birth outcomes. Higher consumption frequency of foods that potentially contain L. monocytogenes was associated with a greater incidence of miscarriage. At the same time, these women had significantly higher intakes of all essential nutrients required during pregnancy compared with those with the lowest consumption. It is important for pregnant women to achieve a balance between adequate nutrient intakes while reducing their risk of listeriosis. Our findings suggest that a moderate consumption of potential risky foods may be the optimal approach. Further research needs to examine this relationship in other cohorts of women and should consider all risky foods as well as the food handling practices of pregnant women. Furthermore, the research undertaken in the present study needs to be replicated in other cohorts that include pregnant women. Examination of this relationship across diverse populations with variable dietary patterns is an important step in informing whether food-based recommendations to reduce the risk of listerosis for pregnant women require revision or not, as information in this area is lacking.

\section{Acknowledgements}

This research was carried out as part of the Australian Longitudinal Study on Women's Health (ALSWH), conducted by the University of Newcastle and the University of Queensland, and funded by Australian Government Department of Health and Ageing. There was no funding for the current analysis, which was undertaken as part of the requirements for BND (Hons), School of Health 
Sciences, University of Newcastle (K.B.P.). C.E.C. was funded by a National Health and Medical Research Council of Australia, Career Development Award Research Fellowship. All authors declare they have no conflicts of interest. C.E.C., A.J.H. and M.L.B. designed the study. K.B.P. and A.J.H. conducted the statistical analyses. K.B.P. drafted the manuscript and all authors contributed to critical review and development of the final manuscript. The authors thank the women who participated and all those who contributed to the ALSWH project.

\section{References}

1. Anderson SA (2001) Symposium on 'Nutritional adaptation to pregnancy and lactation'. Pregnancy as a time for dietary change? Proc Nutr Soc 60, 497-594.

2. Moore VM \& Davies MJ (2005) Diet during pregnancy, neonatal outcomes and later health. Reprod Fertil Dev 17, 341-348.

3. Kind KL, Moore VM \& Davies MJ (2006) Diet around conception and during pregnancy - effects on fetal and neonatal outcomes. Reprod Biomed Online 12, 532-541.

4. Baker D (1998) Mothers, Babies and Health in Later Life. Edinburgh: Churchill Livingstone.

5. Kaiser LL \& Allen LH (2008) Position of the American Dietetic Association: nutrition and lifestyle for a healthy pregnancy outcome. J Am Diet Assoc 108, 553-561.

6. Ministry of Health (2008) Food and Nutrition Guidelines for Healthy Pregnant and Breastfeeding Women: A Background Paper. Wellington: New Zealand Ministry of Health.

7. Williamson CS (2006) Nutrition in pregnancy: briefing paper. Nutr Bull 31, 28-59.

8. Food Standards Australia New Zealand (2004) Listeria and Food: Advice for People at Risk (brochure). Canberra: FSANZ, available at http://www.foodstandards.gov.au/_ srcfiles/Listeria.pdf.

9. Bondarianzadeh D (2007) Food risk to babies: listeriosis. Nutr Today 42, 236-241.

10. OzFoodNet Working Group (2009) Monitoring the incidence and causes of diseases potentially transmitted by food in Australia: annual report of the OzFoodNet Network, 2008. Commun Dis Intell 33, 433-443.

11. Allerberger F \& Wagner M (2010) Listeriosis: a resurgent foodborne infection. Clin Microbiol Infect 16, 16-23.

12. Jackson KA, Iwamoto M \& Swerdlow D (2010) Pregnancyassociated listeriosis. Epidemiol Infect 138, 1503-1509.

13. NSW Food Authority (2006) Food safety during pregnancy (booklet). http://www.foodauthority.nsw.gov.au/_Documents/ consumer_pdf/pregnancy-brochure.pdf (accessed January 2010).

14. Begley A (2002) Barriers to good nutrient intakes during pregnancy: a qualitative analysis. Nutr Diet 59, 175-180.
15. Hure A, Young A, Smith R et al. (2008) Diet and pregnancy status in Australian women. Public Health Nutr 12, 853-861.

16. Rogers I \& Emmett P (1998) Diet during pregnancy in a population of pregnant women in South West England. Eur J Clin Nutr 52, 246-250.

17. Mouratidou T, Ford F, Prountzou F et al. (2006) Dietary assessment of a population of pregnant women in Sheffield, UK. Br J Nutr 96, 929-935.

18. Pick M, Edwards M, Moreau D et al. (2005) Assessment of diet quality in pregnant women using the Healthy Eating Index. J Am Diet Assoc 105, 240-246.

19. Watson P \& McDonald B (2009) Major influences on nutrient intake in pregnant New Zealand women. Matern Child Health J 13, 695-706.

20. National Health and Medical Research Council (2005) Nutrient Reference Values for Australia and New Zealand. Canberra: NHMRC.

21. Brown WJ, Bryson L, Byles JE et al. (1996) Women's Health Australia: establishment of the Australian Longitudinal Study on Women's Health. J Womens Health 5, 467-472.

22. Brown WJ, Bryson L, Byles JE et al. (1998) Women's Health Australia: recruitment for a national longitudinal cohort study. Women Health 28, 23-40.

23. Lee C, Dobson AJ, Brown WJ et al. (2005) Cohort profile: the Australian Longitudinal Study on Women's Health. Int J Epidemiol 34, 987-991.

24. Giles G \& Ireland P (1996) Dietary Questionnaire for Epidemiological Studies (Version 2). Melbourne: the Cancer Council Victoria.

25. Hodge A, Patterson A, Brown W et al. (2000) The Anti Cancer Council of Victoria FFQ: relative validity of nutrient intakes compared with weighed food records in young to middle-aged women in a study of iron supplementation. Aust N Z J Public Health 24, 576-583.

26. NUTTAB95 (1995) Nutrient Data Table for Use in Australia. Canberra: Australian Government Publishing Service.

27. Food Standards Australia New Zealand (2005) Listeria and Food. Commonly Asked Questions. Canberra: FSANZ.

28. Morrison J, Najman J, Williams G et al. (1989) Socioeconomic status and pregnancy outcome: an Australian Study. Br J Obstet Gynaecol 96, 298-307.

29. Rumbold A \& Crowther C (2005) Vitamin C supplementation in pregnancy. Cochrane Database Syst Rev issue 2, CD004072.

30. Hofmeyr GJ, Atallah A \& Duley L (2006) Calcium supplementation during pregnancy for preventing hypertensive disorders and related problems. Cochrane Database Syst Rev issue 3, CD001059.

31. Herbert D, Lucke J \& Dobson A (2009) Pregnancy losses in young Australian women. Findings from the Australian Longitudinal Study on Women's Health. Womens Health Issues 19, 21-29. 